NEWS

\title{
Financial meltdown imperils reactor
}

\section{Faced with a huge budget shortfall, Europe rethinks future of ITER fusion project.}

It has been billed as the solution to tomorrow's energy crunch, but ITER, a massive fusion experiment by seven international partners, is under serious threat from a presentday problem: the financial crisis.

In a meeting on 26 May, the cashstrapped member states of the European Union (EU) were unable to agree on how to find the additional billions needed to finance construction of the giant reactor, which is sited near St-Paullès-Durance, France. The EU is set to contribute $45 \%$ of the construction costs for ITER, which some estimates now put at $€ 15$ billion (US\$19 billion) - three times the 2006 cost estimate (see 'The ITER rollercoaster').

Left unresolved, the impasse in Europe will, at best, delay the project further. At worst, it could cause ITER to unravel entirely.

"I think the momentum of the project may be in very deep trouble," says one non-EU scientist involved with ITER who asked not to be named, citing the experiment's precarious position. "Time is pressing."

ITER has been a 25-year dream for fusion advocates: a step towards turning the promise of fusion - combining hydrogen isotopes into helium - into a practical power source. Fusion

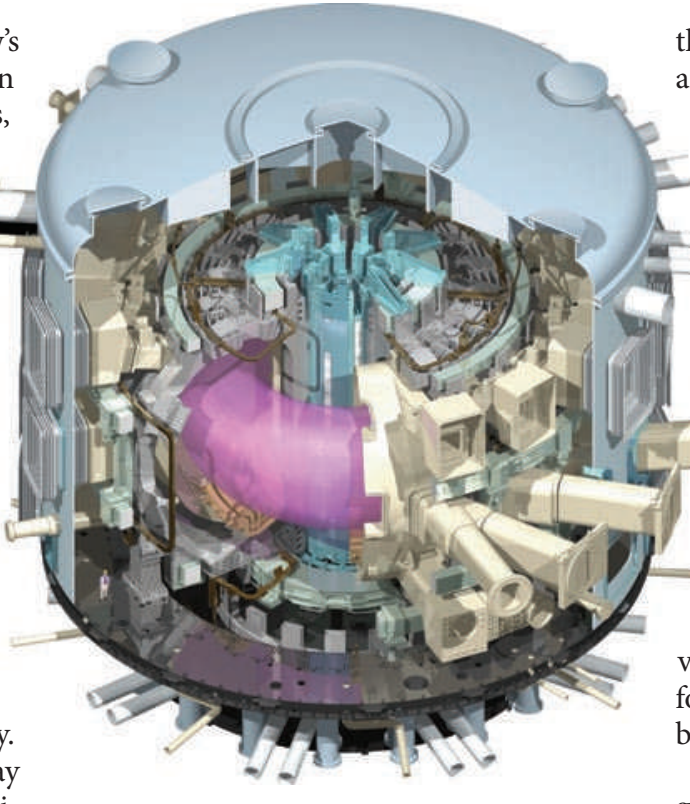

Will the ITER reactor ever have its day in the sun?

releases far more energy than the fission reactions of conventional nuclear power, but it is also more difficult to achieve. The doughnutshaped ITER reactor would use superconducting magnets to heat and squeeze hydrogen until

the device ignites a fusion reaction, releasing around ten times the power it consumes.

In 2006, when the EU, the United States, Russia, South Korea, China, India and Japan agreed to the project in its current form, ITER was estimated to cost around $€ 5$ billion to construct over a decade. But the rising cost of materials, gaps in the original design and the bureaucracy needed to manage the project have caused the cost to balloon (see Nature 459, 488-489; 2009).

On 5 May the European Commission, which manages the project, released a memo that put the price of Europe's share of the construction at around $€ 7.2$ billion, nearly three times the 2006 estimate. The vagaries of how the seven partners budget for the project mean a full price-tag may never be known.

The most pressing problem is a $€ 1$.4-billion gap in Europe's budget for ITER in 2012-13. The commission's 5 May memo called on the 27 member states, which must ultimately pay for ITER, to "provide the additional resources necessary" for the project.

The request could not have come at a worse time for Europe. Faced with an economic crisis in Greece that could spread, the EU has

\section{Researchers track path of oil from rig spill}

With no end in sight for the oil gushing from the explosion site at the Deepwater Horizon drilling rig, anxious US officials are looking to researchers who study the Gulf of Mexico and its idiosyncratic currents to help determine where all the oil is and where it might be heading. Long-term efforts to understand the movement of Gulf waters because of their effect on hurricanes are now being used to address the more immediate question of which regions and ecosystems outside the immediate spill zone are most likely to bear the brunt of a non-stop river of oil.

"This is where a lot of the action is," says Lynn 'Nick' Shay, a physical oceanographer at the University of Miami in Florida. Shay is referring to an expanse of open water visible from the window of the National Oceanic and Atmospheric Administration (NOAA) 'hurricane hunter' research plane that routinely carries him on 9-hour-long sweeps of the Gulf. At this particular spot, some 460 kilometres southeast of the spill, the Gulf's hairpin-shaped Loop Current is pinching off to form a circular eddy about the size of Ireland.

The eddy, a temporary detour from the current's normal path, could well be a lucky break. As the oil spreads, it is gradually becoming entrained in the Loop Current, an offshoot of the Gulf Stream that flows south and east of the spill site off the Louisiana coast towards the opening between Cuba and Florida.

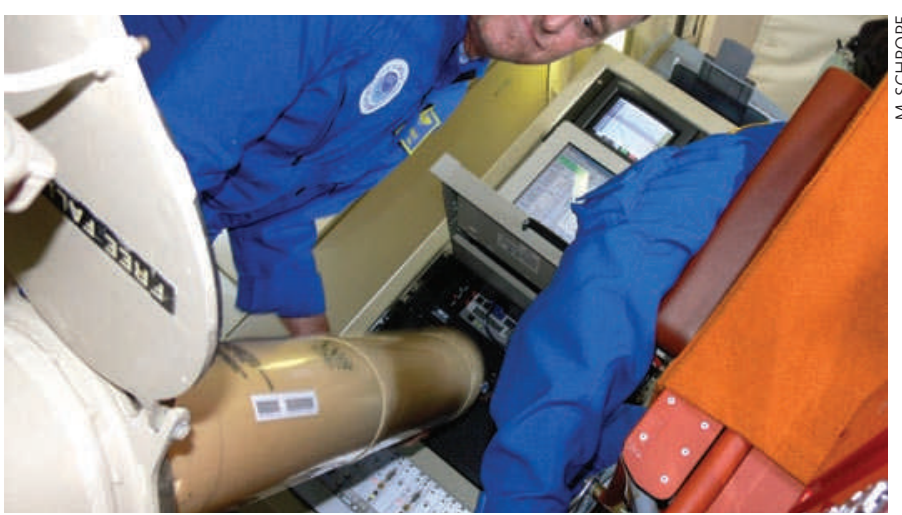

An ocean-monitoring sensor package is about to be dropped from a plane.
The prospect of large amounts of oil moving towards coastlines in that region is a dire one for communities and fisheries, as well as for the sensitive coral reefs. By contrast, oil pulled into the eddy could be sequestered there for months as the vortex drifts westward at "about the speed of Miami traffic", says Shay. Although it would still threaten 


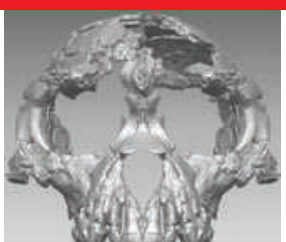

ARDIPITHECUS MAY BE MORE APE THAN HUMAN

Woodland home and ancestry questioned. go.nature.com/wAM1Bs

\section{THE ITER ROLLERCOASTER}

Cost estimates for the beleaguered fusion project have fluctuated wildly over the past two decades.

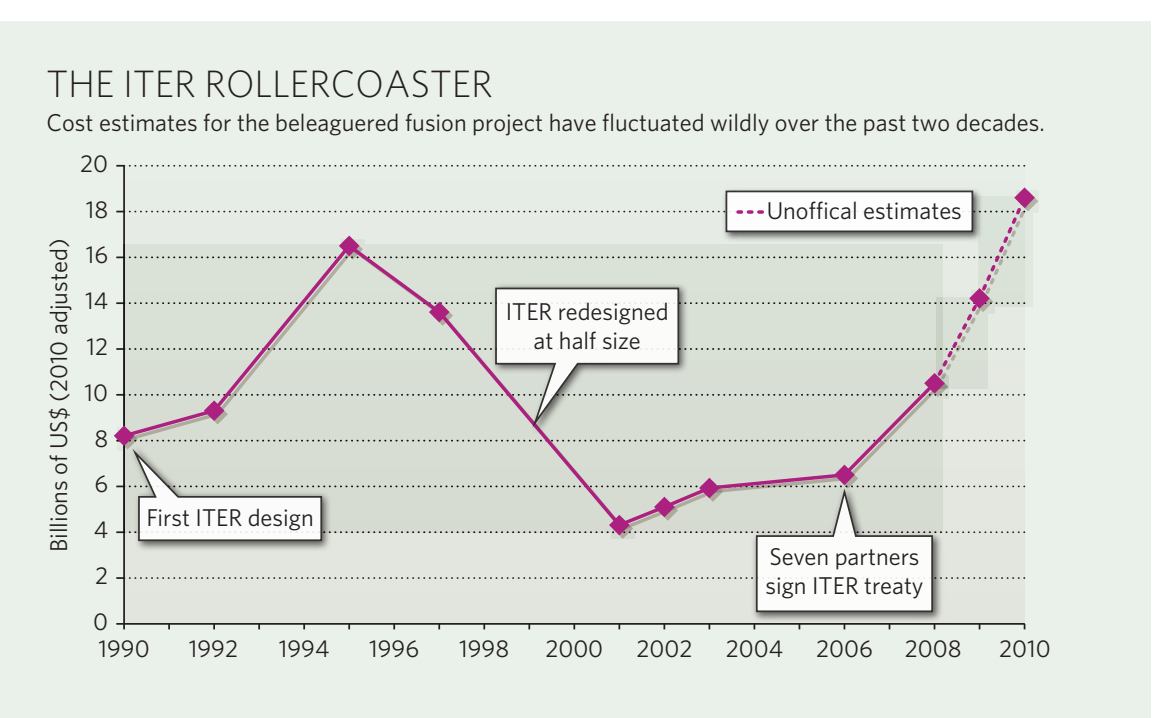

just approved a costly €500-billion bailout package for eurozone countries. Meanwhile, many nations are desperately trying to trim their domestic budgets in an effort to right the continent's troubled finances.

The crunch is so serious that some European states have gone as far as to ask the commission to investigate the possibility of withdrawing from ITER, according to sources familiar with the negotiations. The price of such a withdrawal would probably be in the billions, as the treaty governing ITER requires heavy compensation to other partners.

Mark English, a spokesman for the European Commission, declined to comment on whether member states had asked for an analysis of withdrawal. In a press conference during the most recent meeting, European officials said they remained committed to ITER. "I think that, with vision, we can overcome the difficulties," Máire Geoghegan-Quinn, the European commissioner for research, told reporters on 26 May.

One temporary solution would be a loan from the European Investment Bank to cover the immediate $€ 1$.4-billion budget gap. That would work in the short term, but member states would still have to come up with a plan to cover the full $€ 7.2$-billion costs. Another possibility, floated by Annette Schavan,
Germany's research minister, would beto redesign the machine, possibly building a smaller version.

But scaling back ITER at this stage is unrealistic, says Stephen Dean, president of Fusion Power Associates, a non-profit advocacy group based in Gaithersburg, Maryland. The planned reactor is already half the size that scientists originally hoped it would be, and any further shrinking would risk making the machine too small to achieve its goals.

Europe's member states have formed a task force to discuss how to pay for the project. The group will meet weekly in the run-up to a meeting of the full ITER council on 17 June. If the EU cannot reach an agreement in time, ITER's six other members may decide to delay the council meeting until Europe has found a way forward, insiders say.

Dean says he thinks that ITER's other partners may ultimately have to provide more aid if the project is to stay on track. "If they want the [current] schedule that badly, they're going to have to come up with more money," he adds.

More fundamentally, Dean says, the seemingly endless succession of cost increases and delays may cause a rethink of fusion entirely. "We're supposedly developing a power source that's going to compete with coal and nuclear," he says. But the experience so far does not bode well: "There are serious questions about the affordability of fusion as a whole as a result of ITER.'

Geoff Brumfiel marine life, the effects on coastal ecosystems would be lessened, because there would be more time for evaporation and microbes to help break down the oil. "The question is how much goes each way," says Shay.

Shay's team is helping to answer the question by gathering detailed information on the state of the Loop Current and eddy on its research flights. Every few minutes during a flight, a sensor package about the size of a poster tube is dropped through a hole in the floor of the plane. Depending on which sensor is used, the tube will radio back information on temperature, salinity or current movement as it plunges into the depths.

The deep-water data are important because so little is known about what the currents are doing below the surface - and that's exactly where much of the oil may be hiding, in the form of vast underwater plumes (see Nature 465, 274-275; 2010). As Shay and his team criss-cross the Gulf by air, scientists aboard the $F$. G. Walton Smith research ship are tracking the subsurface spread of layers of what seems to be an oil plume at multiple depths west of ground zero. And two other research groups have just returned from studying other areas of apparent deep oil.

James Cowan, a fisheries biologist at Louisiana State University in Baton Rouge, has been aboard a small charter fishing boat about 120 kilometres northwest of the main spill deploying a remotely operated vehicle to examine water down to about 120 metres. In one large area beneath visible surface oil, says Cowan, "we saw oil all the way down as far as we could go. It was thick enough so that it pretty much covered our camera globe and the lights."

The challenge now is to predict where all that oil will go. Ruoying $\mathrm{He}$, an oceanographer with the ocean observing and modelling group at North Carolina State University in Raleigh, works with an oceancirculation model that takes data such as temperature and wind measurements and tries to forecast the behaviour of the currents in the Gulf and the adjacent portion of the Atlantic. Having built up expertise over years, He's ocean modelling group is one of several teams running ocean-circulation forecast models used by NOAA's Emergency Response Division. NOAA, the lead agency for scientific issues relating to the spill, is using these modelling results to generate its prediction of the oil's movement and so guide local, state and federal responses.

But He acknowledges that lack of data from the deep water makes the entire situation murky. The stricken oil well lies 1,500 metres down, and no one really knows how the oil is distributed at such depths or how well the numerical models of ocean circulation can perform there. "Information from only the surface might be misleading," He says. Yonggang Liu, a physical oceanographer at the University of South Florida in St Petersburg, agrees that the observations are sparse. "We need more data," he says. "Without it, our models are very limited."

In the coming weeks, some of those data will start to trickle in. They will do nothing to stop the oil, but they will be essential in revealing what happens next.

Mark Schrope and Janet Fang 